MARIA ANGÉLICA MACHADO ARROYO

Efeito do letrozol no hipotálamo e gônadas de preás durante o desenvolvimento sexual

São Paulo

2017 


\section{Efeito do letrozol no hipotálamo e gônadas de preás durante o desenvolvimento sexual}

Tese apresentada ao Programa de PósGraduação em Anatomia dos Animais Domésticos e Silvestres da Faculdade de Medicina Veterinária e Zootecnia da Universidade de São Paulo para a obtenção do título de Doutora em Ciências

Departamento:

Cirurgia

Área de concentração:

Anatomia dos Animais Domésticos e Silvestres

Orientador:

Prof. Dr. Antônio Chaves de Assis Neto

São Paulo 
Autorizo a reprodução parcial ou total desta obra, para fins acadêmicos, desde que citada a fonte.

\section{DADOS INTERNACIONAIS DE CATALOGAÇÃO NA PUBLICAÇÃO}

(Biblioteca Virginie Buff D’Ápice da Faculdade de Medicina Veterinária e Zootecnia da Universidade de São Paulo)

Arroyo, Maria Angélica Machado

Efeito do letrozol no hipotálamo e gônadas de preás durante o desenvolvimento sexual. / Maria Angélica Machado Arroyo. -- 2017

$35 \mathrm{f}$ : : il.

Tese (Doutorado) - Universidade de São Paulo. Faculdade de Medicina Veterinária e Zootecnia. Departamento de Cirurgia, São Paulo, 2017.

Programa de Pós-Graduação: Anatomia dos Animais Domésticos e Silvestres.

Área de concentração: Anatomia dos Animais Domésticos e Silvestres.

Orientador: Prof. Dr. Antônio Chaves de Assis Neto.

1. Aromatase. 2. Estrógenos. 3. Anabolizante. 4. Infertilidade. 5. Displasia. I. Título. 


\section{CERTIFICADO}

Certificamos que a proposta intitulada "Efeito do letrozol no hipotálamo e gônadas de preás durante o desenvolvimento sexual" protocolada sob o CEUA n 7781180516, sob a responsabilidade de Antônio Chaves de Assis Neto e equipe; Maria Angélica Machado Arroyo; Moacir Franco de Oliveira - que envolve a produção, manutenção e/ou utilização de animais pertencentes ao filo Chordata, subfilo Vertebrata (exceto o homem), para fins de pesquisa científica ou ensino - está de acordo com os preceitos da Lei 11.794 de 8 de outubro de 2008, com o Decreto 6.899 de 15 de julho de 2009, bem como com as normas editadas pelo Conselho Nacional de Controle da Experimentação Animal (CONCEA), e foi aprovada pela Comissão de Ética no Uso de Animais da Faculdade de Medicina Veterinária e Zootecnia da Universidade de São Paulo (CEUA/FMVZ) na reunião de 15/03/2017.

We certify that the proposal "Effect of letrozole on hypothalamus and gonads of Spix's yellow-toothed cavy during the sexual development ", utilizing 48 Brazilian wild species (males and females), protocol number CEUA 7781180516, under the responsibility of Antônio Chaves de Assis Neto and team; Maria Angélica Machado Arroyo; Moacir Franco de Oliveira - which involves the production, maintenance and/or use of animals belonging to the phylum Chordata, subphylum Vertebrata (except human beings), for scientific research purposes or teaching - is in accordance with Law 11.794 of October 8, 2008, Decree 6899 of July 15, 2009, as well as with the rules issued by the National Council for Control of Animal Experimentation (CONCEA), and was approved by the Ethic Committee on Animal Use of the School of Veterinary Medicine and Animal Science (University of São Paulo) (CEUA/FMVZ) in the meeting of 03/15/2017.

Finalidade da Proposta: Pesquisa

Vigência da Proposta: de 05/2016 a 07/2017

Area: Anatomia dos Animais Domésticos E Silvestres

Origem: Não aplicável biotério

\begin{tabular}{|c|c|c|c|c|c|c|}
\hline Espécie: & Espécies silvestres brasileiras & sexo: & Machos e Fêmeas & idade: & 15 a 120 dias & $\mathrm{N}: \quad 48$ \\
\hline Linhagem: & Galea spixii & & & Peso: & 50 a $300 \mathrm{~g}$ & \\
\hline
\end{tabular}

Registro IBAMA/Sisbio/Etc: Autorização SISBIO n²41910-4, data de emissão 22/02/2016. CEMAS, Mossoró/RN Registro IBAMA n 1478912.

Método de Captura: Manual, com eventual auxilio de puçá. Autorização SISBIO n² 41910-4, 22/02/2016.

Resumo: Objetiva-se avaliar o efeito do letrozol no hipotálamo e gônadas de preás durante o desenvolvimento sexual. Para tanto, induziremos o bloqueio da enzima citocromo P450 aromatase utilizando o letrozol como inibidor da biossíntese de estrógenos. A partir dos 15 dias pós-natal, os animais receberão a dose de letrozol oral diluída de $0,01 \mathrm{~g} / \mathrm{kg}$ de peso corporal, semanalmente. Nas fases pré-púbere (30 dias), púbere (45; 90 dias) e adulto (120 dias) serão coletados os testículos; ovários; e encéfalo. Os fragmentos serão processados para histologia, imunohistoquímica e PCR. De acordo com a metodologia adotada, é esperado que preás machos e fêmeas, tratados com letrozol, apresentem deficiências no desenvolvimento do eixo hipotalâmico-gonadal, bem como no ciclo reprodutivo, devido à deficiência de estrógeno.

Local do experimento: Manutenção dos animais e coleta: Centro de Manejo de Animais Silvestres - CEMAS, Mossoró/RN (Registro IBAMA $n^{\circ}$ 1478912). Processamento e execução do material coletado: Anatomia dos Animais Domésticos e Silvestres, Faculdade de Medicina Veterinária e Zootecnia, USP, São Paulo/SP

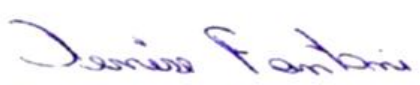

Profa. Dra. Denise Tabacchi Fantoni

Presidente da Comissão de Ética no Uso de Animais

Faculdade de Medicina Veterinária e Zootecnia da Universidade de São Paulo

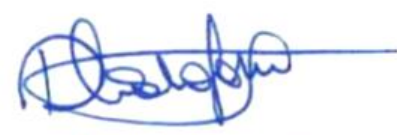

Roseli da Costa Gomes

Secretaria Executiva da Comissão de Ética no Uso de Animais Faculdade de Medicina Veterinária e Zootecnia da Universidade de São Paulo

Av. Prof. Dr. Orlando Marques de Paiva, 87. Cidade Universitária: Armando de Salles Oliveira CEP 05508-270 Sáo Paulo/SP - Brasil - tel: 55 (11) 3091-7676/0904 / fax: 55 (11) 3032-2224 Horário de atendimento: $2{ }^{2}$ a $6^{\circ}$ das $8 \mathrm{~h}$ as $17 \mathrm{~h}$ : e-mail: ceuavet@usp.br 


\section{FOLHA DE AVALIAÇÃO}

Autor: ARROYO, Maria Angélica Machado

Título: Efeito do letrozol no hipotálamo e gônadas de preás durante o desenvolvimento sexual

Tese apresentada ao Programa de PósGraduação em Anatomia dos Animais Domésticos e Silvestres da Faculdade de Medicina Veterinária e Zootecnia da Universidade de São Paulo para obtenção do título de Doutora em Ciências

Data:

\section{Banca Examinadora}

Prof. Dr.

Instituição: Julgamento:

Prof. Dr.

Instituição: Julgamento:

Prof. Dr.

Instituição: Julgamento:

Prof. Dr.

Instituição: Julgamento:

Prof. Dr.

Instituição: Julgamento: 
À Maria Inês Cardenas Machado (in memoriam).

À minha família. 


\section{AGRADECIMENTOS}

Adriana Cecilia Machado, Lucas Machado Arroyo e Pedro Machado Arroyo (e Monet), obrigada por andarem de mãos dadas comigo e me abraçarem, sempre.

Juliana Cardenas Machado Gonçales, Luciana Cardenas Machado Casali, Cassiana Cardenas Machado, e família, obrigada pelo cuidado e amor que vocês têm para comigo.

Marcos Antonio Momo, meu amigo, agradeço ao apoio que a vida assim permitiu.

Professor Dr. Antônio Chaves de Assis Neto, uma das sortes que tive na vida, obrigada por ter confiado em meu trabalho.

Professor Dr. Moacir Franco de Oliveira, colaborador e parceiro. Obrigada pela confiança e por abrir as portas de Mossoró a mim. Sou grata a sua família que, também, me recebeu tão gentilmente.

Felipe Venceslau Câmara e orientados do Professor Moacir, meus braços em Mossoró quando não pude estar presente, obrigada.

Ao Centro de Manejo de Animais Silvestres (CEMAS) e Universidade Federal Rural do Semiárido (UFERSA), Mossoró/RN, agradeço a disponibilidade e parceria.

Ao Programa de Pós-Graduação em Anatomia dos Animais Domésticos e Silvestres sou grata à oportunidade.

Agradeço a Fundação de Amparo à Pesquisa do Estado de São Paulo (FAPESP), processo nำ 2013/22708-5, financiadora desta pesquisa.

Felizmente são tantas as pessoas que cruzaram o meu caminho. A cada um que, verdadeiramente, contribuiu para o meu trabalho e crescimento pessoal...

Obrigada. 
"Descobrir consiste em olhar para o que todo mundo está vendo e pensar uma coisa diferente."

Roger Von Oech 


\section{RESUMO}

ARROYO, M. A. M. Efeito do letrozol no hipotálamo e gônadas de preás durante o desenvolvimento sexual. [Effect of letrozole in hypothalamus and gonads of spix's yellow-toothed cavy during sexual development]. 2017. $35 \mathrm{f}$. Tese (Doutorado em Ciências) - Faculdade de Medicina Veterinária e Zootecnia, Universidade de São Paulo, São Paulo, 2017.

O letrozol é usado como terapêutico em desordens reprodutivas provocadas pelos altos níveis de estrógenos. A enzima citocromo P450 aromatase biossintetiza estrógenos a partir dos andrógenos em tecidos com capacidade esteroidogênica, como o cérebro, testículo e ovário. O objetivo do nosso estudo foi avaliar se o letrozol afeta o desenvolvimento das principais vias de controle reprodutivo de preás machos e fêmeas. Para tanto, consideramos o ganho de peso corporal, do testículo, do ovário e do cérebro, a progressão morfológica da espermatogênese e da foliculogênese, bem como a atividade enzimática da citocromo P450 aromatase nesses tecidos, comparado-os entre os grupos experimentais de machos e fêmeas. Os preás receberam $0,01 \mathrm{~g} / \mathrm{kg}^{-1}$ de letrozol diluído, via oral, semanalmente, até as idades de 30, 45, 90 e 120 dias. O letrozol aumentou o ganho de peso corporal, das gônadas e do cérebro. Também, prejudicou a formação do epitélio germinativo testicular e estratificou o epitélio de revestimento do ovário. Ainda, o inibidor pode alterar os campos neurais relacionados às zonas de aromatização. E alterou os sítios de atuação da aromatase nas gônadas. Concluímos que o uso prolongado do letrozol pode ocasionar efeito anabólico, infertilidade de machos, induzir a displasia ovariana em fêmeas e alterar os sítios de atuação da aromatase.

Palavras-chave: Aromatase. Estrógenos. Anabolizante. Infertilidade. Displasia. 


\begin{abstract}
ARROYO, M. A. M. Effect of letrozole in hypothalamus and gonads of spix's yellow-toothed cavy during sexual development. [Efeito do letrozol no hipotálamo e gônadas de preás durante o desenvolvimento sexual]. 2017. 35 f. Tese (Doutorado em Ciências) - Faculdade de Medicina Veterinária e Zootecnia, Universidade de São Paulo, São Paulo, 2017.
\end{abstract}

Letrozole is used as a therapeutic in reproductive disorders caused by high estrogen levels. The enzyme cytochrome P450 aromatase biosynthesizes estrogens from androgens on tissues with steroidogenic capacity such as brain, testis and ovary. The objective of our study was to evaluate whether letrozole affects the development of the main reproductive control pathway of male and female spix's yellow-toothed cavy. For this, we considered body weight, testis, ovary and brain gain, spermatogenesis and folliculogenesis, as well as the enzymatic activity of cytochrome P450 aromatase in these tissues compared to experimental groups of males and females. The cavies received dilute letrozole orally $\left(0,01 \mathrm{~g} / \mathrm{kg}^{-1}\right)$, once a week, until 30, 45, 90 and 120 days. Letrozole increased body weight, gonad and brain gain. Also, it impaired the formation of the testicular germinal epithelium and epithelium of ovary. Furthermore, the inhibitor may alter the neural fields related to the aromatization zones and changed the sites of aromatase in the gonads. We concluded that prolonged use of letrozole may result in an anabolic effect, male infertility, induce ovarian dysplasia in females, and alter the sites of aromatase activity.

Keywords: Aromatase. Estrogens. Anabolic effect. Infertility. Dysplasia. 


\section{SUMÁRIO}

1 INTRODUÇÃO

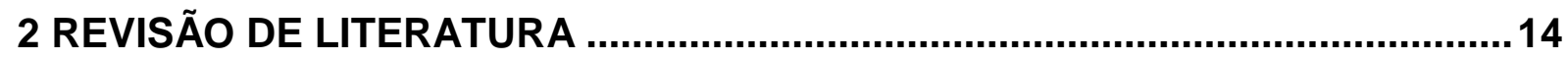

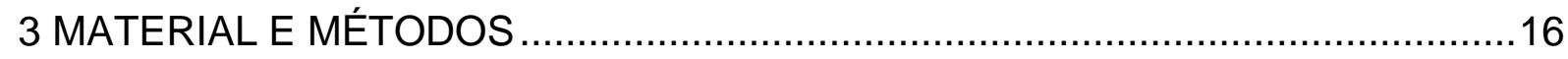

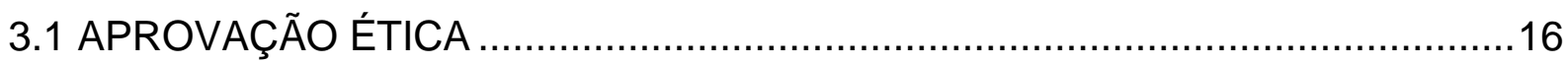

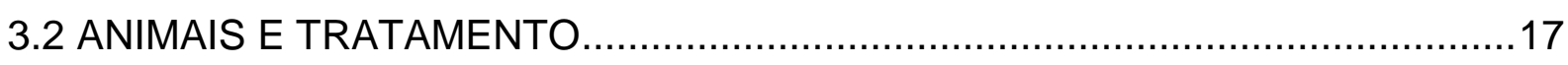

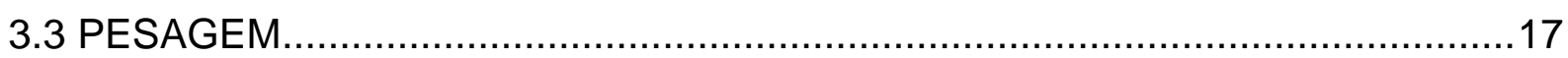

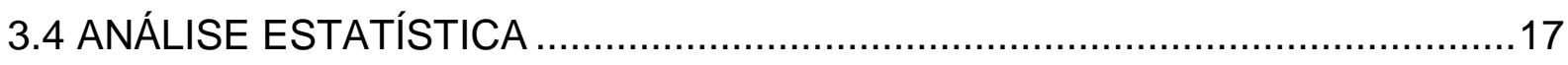

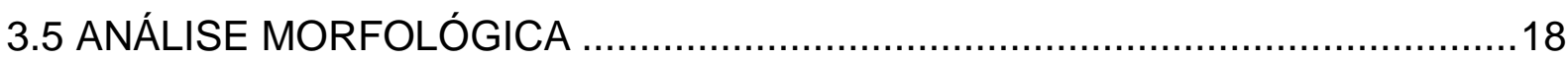

3.6 IMUNOLOCALIZAÇÃO DA ENZIMA CITOCROMO P450 AROMATASE ...........18

3.7 QUANTIFICAÇÃO DA ENZIMA CITOCROMO P450 AROMATASE …..............19

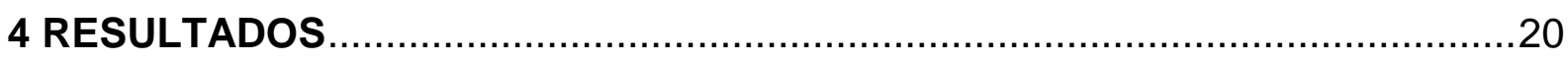

4.1 EFEITO DO LETROZOL NO GANHO DE PESO CORPORAL .........................20

4.2 EFEITO DO LETROZOL NO GANHO DE PESO DO OVÁRIO E DO TESTÍCULO

4.3 EFEITO DO LETROZOL NO GANHO DE PESO DO CÉREBRO ......................22

4.4 EFEITO DO LETROZOL NO DESENVOLVIMENTO MORFOLÓGICO DO

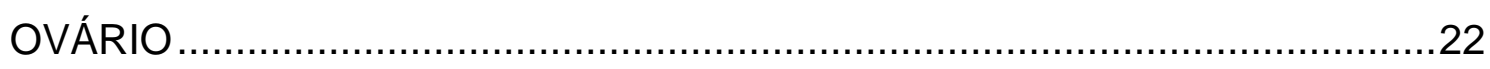

4.5 EFEITO DO LETROZOL NO DESENVOLVIMENTO MORFOLÓGICO DO

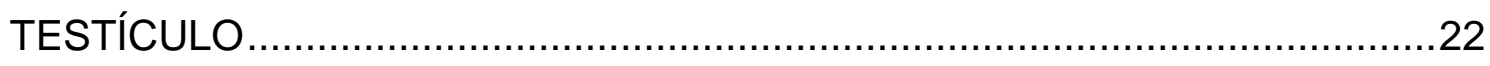

4.6 EFEITO DO LETROZOL NA MORFOLOGIA CEREBRAL ...............................24

4.7 EFEITO DO LETROZOL NA IMUNOLOCALIZAÇÃO DA ENZIMA CITOCROMO

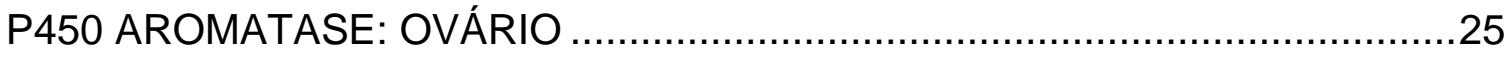

4.8 EFEITO DO LETROZOL NA IMUNOLOCALIZAÇÃO DA ENZIMA CITOCROMO

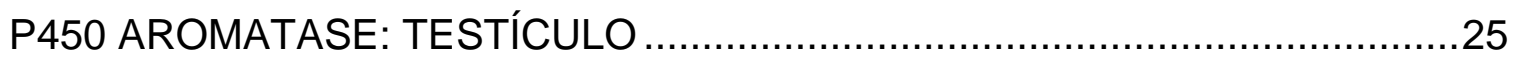

5 DISCUSSÃO

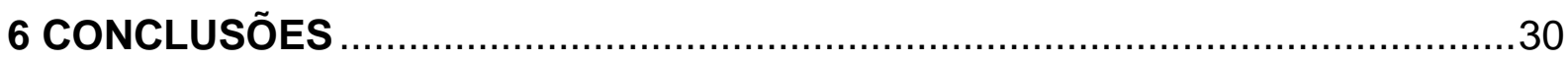

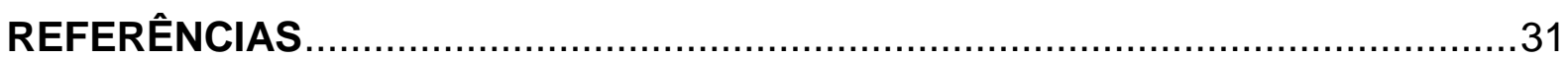




\section{INTRODUÇÃO}

O letrozol é um composto que tem a função específica de inibir a síntese de estrógenos por meio do bloqueio da ação da enzima citocromo P450 aromatase sem afetar outras vias esteroidogênicas (LEPHART, 1996; BHATNAGAR, 2007). Essa enzima, por sua vez, é responsável pela biogênese da estrona e do estradiol a partir dos hormônios androgênicos androstenediona e testosterona, respectivamente (SANTOS et al., 2015b) (Figura 1). Portanto, o uso do letrozol é um recurso que permite o estudo in vivo da incumbência e a avaliação dos sítios de atuação da aromatase, bem como dos efeitos passíveis da inibição desta enzima ocasionados pelo desequilíbrio da razão entre andrógenos e estrógenos nos mais diversos tecidos.

Figura 1 - Esteroidogênese simplificada. Em destaque a função da enzima citocromo P450 aromatase, biossintetizadora de hormônios estrogênicos a partir dos hormônios androgênicos

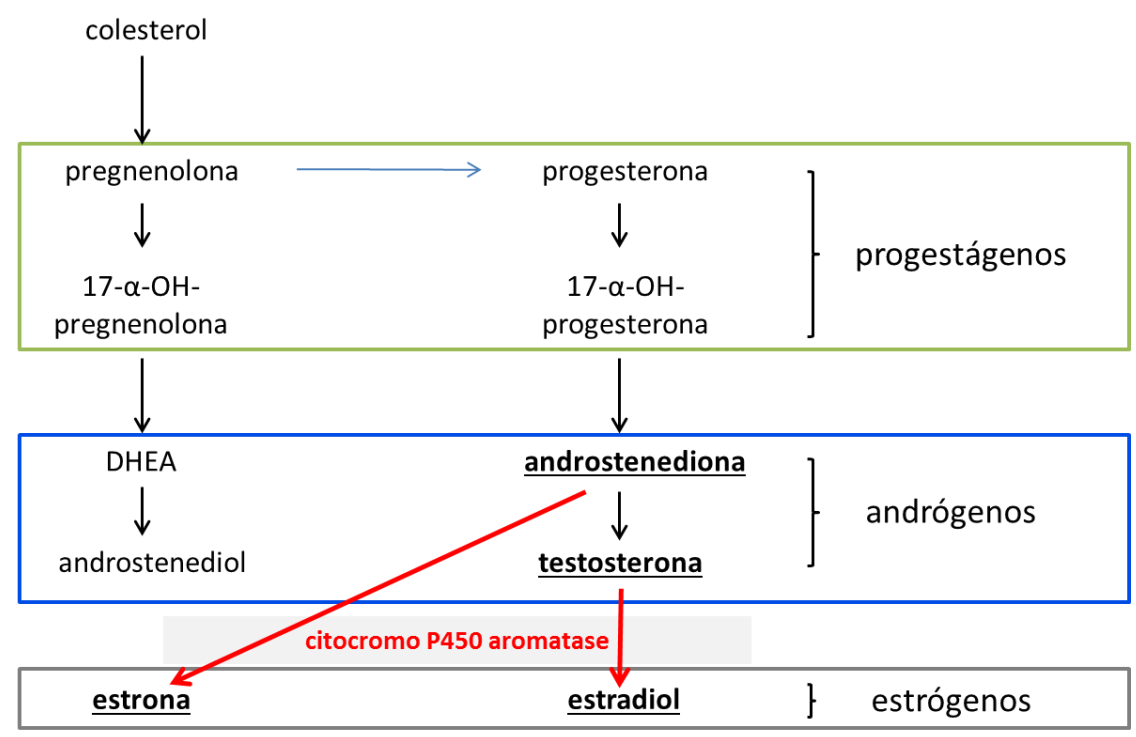

Fonte: (ARROYO, 2017)

A aromatase está envolvida com o desenvolvimento de núcleos de dimorfismos sexuais, conhecidas como zonas de aromatização, encontradas na região hipotalâmica de muitas espécies. As zonas de aromatização parecem estar relacionadas ao controle da reprodução e do comportamento sexual, descritas em mamíferos, anfíbios, aves, peixes e répteis (CORBIN et al., 2009; ROSELLI; STORMSHAK, 2011). No mais, esta enzima também pode induzir o 
desenvolvimento folicular e da espermatogênese, uma vez que foi encontrada nas gônadas de diversas espécies (CONLEY; HINSHELWOOD, 2001) e mantém a proporção fisiológica entre andrógenos e estrógenos nestes tecidos esteroidogênicos, inferindo diretamente sobre a fertilidade.

A aplicabilidade do letrozol como alternativa terapêutica a tratamentos de desordens reprodutivas, incluindo neoplasias, síndrome do ovário policístico e 0 hipogonadismo, vem sendo bastante difundida (ORTEGA et al., 2013; VERMA; KRISHNA, 2016). Estudos comparativos utilizando diversos inibidores de aromatase (HAYNES et al., 2003; LØNNING, 2003; BHATNAGAR, 2007) demonstraram que o letrozol é a mais potente droga com competência seletiva para impedir a síntese de estrógeno intracelular, reduzindo significativamente esses níveis hormonais (BHATNAGAR, 2007).

Não obstante, existe uma abrangência na literatura quanto à dosagem do letrozol para roedores (Tabela 1 ). Os efeitos associados a estes tratamentos compreendem a modificações na expressão de diversos receptores e proteínas, bem como a redução da expressão da aromatase e dos níveis de estradiol (KONDAREWICZ et al., 2011; LIU et al., 2000; PILUTIN et al., 2014).

Tabela 1 - Estudos que avaliaram os efeitos da redução dos estrógenos em ratos machos e fêmeas, em diversas idades e doses.

\begin{tabular}{c|c|c}
\hline Sexo e idade de aplicação & Dose & Referência \\
\hline Machos adultos & $1 \mathrm{mg} / \mathrm{kg}$, por 6 meses & $\begin{array}{c}\text { Kondarewicz et al. (2011); } \\
\text { Pilutin et al. (2014) }\end{array}$ \\
$\begin{array}{c}\text { Fêmeas prenhes, } 10 \text { dias de } \\
\text { gestação - avaliação dos } \\
\text { filhotes machos }\end{array}$ & 0,31 e $0,56 \mu \mathrm{g} / \mathrm{kg} / \mathrm{ml}$ & $\begin{array}{c}\text { Olvera-Hernández; Chavira; } \\
\text { Fernández-Guasti (2015) }\end{array}$ \\
$\begin{array}{c}\text { Fêmeas prenhes, 21 dias de } \\
\text { gestação - avaliação dos } \\
\text { filhotes machos }\end{array}$ & $1 \mathrm{mg} / \mathrm{kg}$ & Gerardin et al. (2008) \\
$\begin{array}{c}\text { Machos e fêmeas jovens } \\
\text { Fêmeas }\end{array}$ & 0,$003 ; 0,03 ; 0,3 \mathrm{mg} / \mathrm{kg} / \mathrm{dia}, 84$ & dias \\
& $1 \mathrm{mg} / \mathrm{kg}, 21$ dias & Pouliot et al. (2013)
\end{tabular}
Fonte: (ARROYO, 2017)

Ainda, o bloqueador da aromatase alterou a morfologia testicular, incluindo: enforcamento das células germinativas, formação de células gigantes e de vacúolos no epitélio seminífero, além de conglomerados de células em degeneração, invaginação de membrana citoplasmática e acúmulo de lipofuscina nas células de 
Leydig (KONDAREWICZ et al., 2011; PILUTIN et al., 2014), gerando retardo nas funções reprodutivas de machos (POULIOT et al., 2013). Em fêmeas, o letrozol aumentou o volume do ovário, córtex, cistos e corpo lúteo, diferentemente das células do oócito e da granulosa (NOORAFSHAN et al., 2013). Também, o bloqueio da aromatização dos andrógenos pré-natal mostrou ter importante papel no estabelecimento do padrão de preferência sexual, comportamento sexual e excitação de machos (OLVERA-HERNÁNDEZ; CHAVIRA; FERNÁNDEZ-GUASTI, 2015), prejudicando a masculinização do hipotálamo (GERARDIN et al., 2008). Ainda assim não são compreendidos os efeitos do uso contínuo do letrozol sobre o desenvolvimento da fertilidade e da reprodução.

Neste sentido, o preá (Galea spixii) (Figura 2) vem se destacando como modelo experimental em diversos estudos sobre fenômenos reprodutivos que acometem, inclusive, humanos. Roedor silvestre da subordem dos Histricomorfos, este animal alcança $23,5 \mathrm{~cm}$ de comprimento e pode pesar até $405 \mathrm{~g}$ quando adulto. Facilmente criado em cativeiro, o ciclo estral do preá dura 15 dias, em média (SANTOS et al., 2015a), enquanto a gestação é de 48 dias, podendo parir até 4 filhotes (OLIVEIRA et al., 2008). O macho, por sua vez, atinge a puberdade por volta dos 45 dias de idade (SANTOS et al., 2014). Geograficamente se distribui, principalmente, em todo o território brasileiro e na Bolívia. Regiões carentes do Nordeste brasileiro têm o hábito de consumir a carne do preá, especialmente no complexo da Caatinga, por serem fontes alternativas de proteína às populações locais (SANTOS et al., 2015a).

Figura 2 - Preá, Galea spixii

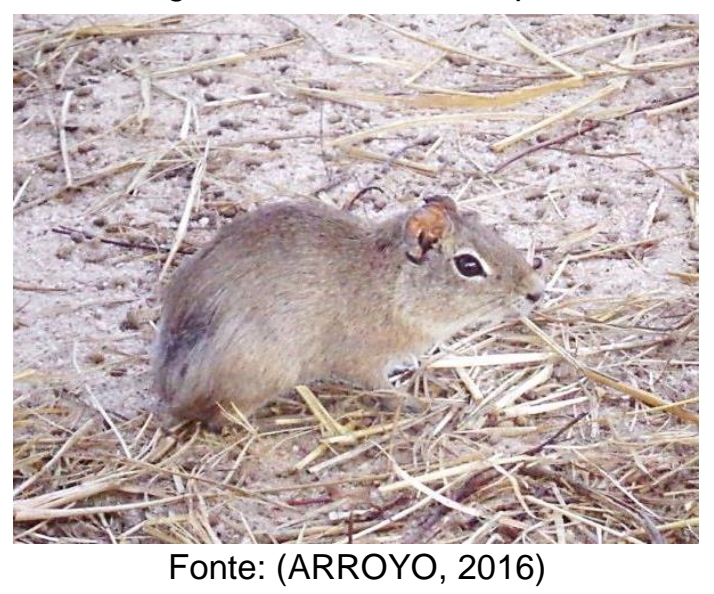


Isto posto, nós avaliamos se a ingestão contínua do letrozol afeta o desenvolvimento das principais vias de controle reprodutivo de preás machos e fêmeas. Destaca-se, também, o fato desta espécie possuir a genitália externa masculinizada (SANTOS et al., 2014; 2016). A análise dos efeitos do letrozol sobre as zonas de aromatização hipotalâmicas e das gônadas durante o desenvolvimento sexual dá suporte à compreensão dos fenômenos fisiológicos pós-natal a esta particularidade.

A escolha da metodologia da aplicação do letrozol, bem como a dose utilizada, se deu com base em nossos estudos prévios com cutias (dados não publicados). Ressaltamos a importância clínica do nosso estudo, uma vez que este medicamento é utilizado comercialmente. Ainda, visamos complementar outras pesquisas de ordem reprodutiva, elucidando o papel da aromatase, com o propósito de induzir a manipulação desta enzima para a implementação biotecnológica na reprodução de diversas espécies.

\section{REVISÃO DE LITERATURA}

O equilíbrio hormonal entre andrógenos e estrógenos é essencial para o adequado desenvolvimento das características reprodutivas, tanto em machos como em fêmeas (SANTOS et al., 2015b). O letrozol é um composto altamente específico capaz de ocasionar uma desproporção na razão entre esses hormônios esteroides, uma vez que bloqueia a ação da enzima citocromo P450 aromatase sem afetar outras vias esteroidogênicas (BHATNAGAR, 2007). Esta enzima, por sua vez, atua em diversos tecidos com capacidade esteroidogênica como gônadas e cérebro, biossintetizando estrógenos a partir dos andrógenos (SANTOS et al., 2015b).

Estudos demonstraram a eficácia terapêutica do uso do letrozol para reverter enfermidades reprodutivas relacionadas à infertilidade, ocasionadas pela descompensação hormonal, como o hipogonadismo (RAMBHATLA; MILLS; RAJFER, 2016). Contudo, não são esclarecidos os efeitos deste antiestrogênico nas atividades gonadais por longos períodos. Sabe-se que a redução dos níveis de estrógenos pode acarretar em efeito anabólico periférico (ORTEGA et al., 2013), 
inclusive nas gônadas, bem como prejudicar a espermatogênese (VERMA; KRISHNA, 2016) e ocasionar a displasia ovariana (LIMA et al., 2014).

O preá vem sendo utilizado como modelo biológico para a compreensão dos fenômenos relativos às características reprodutivas, bem descritas recentemente (PRAXEDES et al., 2015; SANTOS et al., 2012; 2013; SANTOS et al., 2014; 2015a; 2016; 2017), embora pouco se conheça acerca da esteroidogênese reprodutiva da espécie (SANTOS et al., 2017). Neste sentido, o uso do letrozol auxiliará na assimilação dos efeitos da inibição da aromatase e diminuição dos níveis de estrógenos sobre 0 desenvolvimento reprodutivo de outras espécies de histricomorfos, servindo de apoio para o esclarecimento de processos que possam inferir na fisiologia e em doenças de ordem reprodutiva em humanos.

Além disso, a atividade da aromatase foi investigada e descrita em diversas áreas do cérebro envolvidas, principalmente, no controle neuroendócrino da reprodução, incluindo comportamento e diferenciação sexual de machos e fêmeas (CORBIN et al., 2009). Estas regiões são denominadas zonas de aromatização (ROSELLI; STORMSHAK, 2011). Ainda, a aromatase também está relacionada à secreção de gonadotrofinas, humor e status afetivo, e reparo de lesões neurais (GARCIA-SEGURA, 2008). Compreendem-se as regiões do hipotálamo, área préóptica, amigdala, hipocampo e córtex cerebral (ROSELLI et al., 1998). Portanto, variações no adequado funcionamento da aromatase alteram o equilíbrio entre as classes hormonais e influenciam diretamente o fenótipo reprodutivo.

O campo neural responsável pelo comportamento reprodutivo dos machos é organizado durante a vida fetal (ROSELLI; STORMSHAK, 2011) devido a sua exposição à testosterona. Nas fêmeas, a alta dosagem deste hormônio leva à masculinização da genitália externa no período fetal (SANTOS et al., 2017) e a alteração no comportamento de cópula quando adultas (ROSELLI; STORMSHAK, 2011). Assim, recursos que permitem a modificação dos níveis de aromatização, como o uso do letrozol, auxiliam na elucidação do papel desta enzima no cérebro e dos fatores relacionados ao dimorfismo sexual pós-natal. Não são conhecidos os seus efeitos no desenvolvimento reprodutivo de ambos os sexos associados às zonas de aromatização cerebral. Tais regiões parecem ser maiores em machos que em fêmeas (LEPHART, 1996). Esta diferença pode estar relacionada à abundância hormonal de andrógenos e estrógenos, além dos níveis de expressão da citocromo P450 aromatase no hipotálamo. Deste modo, a atividade desta enzima no cérebro 
não é uniforme, mas detectável nos neurônios das regiões hipotalâmicas. Comparando-se a outros tecidos a ação da aromatase é pequena, dependendo, ainda, do estágio do desenvolvimento (CONLEY; HINSHELWOOD, 2001).

Algumas espécies apresentam variações anatômicas naturais quanto ao desenvolvimento genital da fêmea, desencadeadas pelo excesso de andrógenos. É o caso da hiena (GLICKMAN et al., 2006), da toupeira (BARRIONUEVO et al., 2004), da lêmure (DREA, 2007) e do preá (SANTOS et al., 2014). Este último, especialmente, se destaca como modelo experimental na elucidação desses fenômenos. Sabe-se que o aumento da concentração dos hormônios androgênicos durante a prenhes desta espécie pode agir no processo de virilização da genitália externa da fêmea (SANTOS et al., 2017), caracterizada por uma membrana de oclusão vaginal e clitóris transpassado pela uretra (SANTOS et al., 2014). Ainda, a fêmea é agressiva quando em estro, e escolhe o macho para o acasalamento (ADRIAN; SACHSER, 2011).

Portanto, nós avaliamos se o uso prolongado do letrozol afeta 0 desenvolvimento dos fenótipos reprodutivos pós-natal de preás. Para tanto, consideramos o ganho de peso corporal, do testículo, do ovário e do cérebro, a progressão morfológica da espermatogênese e da foliculogênese, bem como a atividade enzimática da citocromo P450 aromatase nas gônadas e no cérebro, comparada entre os grupos experimentais de machos e fêmeas.

\section{MATERIAL E MÉTODOS}

\subsection{APROVAÇÃO ÉTICA}

Os animais e procedimentos foram aprovados pelo Sistema de Autorização e Informação em Biodiversidade - SISBIO no 41910-4 e Comissão de Ética do Uso de Animais - CEUA FMVZ/USP no 7781180516. 


\subsection{ANIMAIS E TRATAMENTO}

Os preás (Galea spixii) foram manejados aos 15 dias pós-natal. 24 animais de cada sexo foram divididos igualmente em grupo tratado e controle. Nesta mesma idade receberam a primeira dose de letrozol (Femara $\AA$ ), continuada semanalmente até as idades de 30, 45, 90 e 120 dias. Cada comprimido com o princípio ativo letrozol (2,5 mg) foi macerado, pesado a $0,01 \mathrm{~g} / \mathrm{kg}^{-1}$ de peso corporal, diluído em 0,5 $\mathrm{ml}$ de água destilada, homogeneizado e fornecido individualmente via oral com seringa. Os preás foram anestesiados com $0,3 \mathrm{ml}$ de quetamina e 0,3 $\mathrm{ml}$ de xilazina, e eutanasiados com $0,4 \mathrm{ml}$ de cloreto de potássio intratorácico. Então, os animais foram pesados. O testículo e o ovário direito foram coletados, pesados, fixados em paraformaldeído $4 \%$ por 24 horas e seccionados. O cérebro foi coletado e pesado. Posteriormente, foi dividido em dois hemisférios, direito e esquerdo, na região da fissura mediana. O hemisfério direito foi fixado em paraformaldeído 4\% por 24 horas. A região hipotalâmica do hemisfério esquerdo foi dissecada, delimitada rostralmente pelo quiasma óptico, caudalmente pelos corpos mamilares, e próximo ao III ventrículo, e, juntamente com o testículo e ovário esquerdo, foram mantidos na solução RNAlater® Solution (Ambion; 500 mL, P/N AM7021; L/N 1410060; USA) a $4^{\circ}-8^{\circ} \mathrm{C}$ por uma semana. Posteriormente foram mantidos congelados a $-80^{\circ} \mathrm{C}$.

\subsection{PESAGEM}

O peso foi utilizado para avaliar indiretamente o efeito periférico e/ou tecidual da ação do letrozol em longo prazo. Os preás foram pesados antes da eutanásia (balança Elgin WT21-LCD). O testículo e o ovário direito, bem como o cérebro foram pesados durante a coleta (balança analítica Bel M214A).

\subsection{ANÁLISE ESTATÍSTICA}


Os pesos médios corporal, testicular, ovariano e cerebral de animais de 30 dias foram comparados com as idades de 45, 90 e 120 dias, nos grupos tratados com letrozol e nos grupos controle; e fizemos a comparação entre os grupos tratado com letrozol e controle dentro dos diferentes grupos etários. Utilizamos o teste de correlação Bonferroni (software IBM SPSS Statistics ${ }^{\circledR}$ ). $P<0,05$ foi considerado significante.

\subsection{ANÁLISE MORFOLÓGICA}

Secções do testículo e ovário, bem como o hemisfério cerebral direito foram fixadas em paraformaldeído 4\% por 24 horas, desidratadas em diluições graduadas de etanol (70-100\%) e embebidas em parafina. Para coloração, secções de $5 \mu \mathrm{m}$ foram cortadas e montadas em lâminas foscas Precision®.

As colorações Hematoxilina e Eosina (H/E) foram realizadas para investigar a morfologia dos tecidos analisados de animais controle e tratados com letrozol. Seguindo a desparafinização em xilol (Sigma-Aldrich, Wicklow, Ireland; temperatura ambiente [RT], 2 x 10 minutos [min]), reidratação em graduação decrescente de etanol (RT, 2 x 5 min 100\%; 5 min 90\%, 5 min 80\%, 5 min 70\%) e água destilada (RT, $5 \mathrm{~min}$ ), as lâminas foram coradas com hematoxilina (Vetec, Rio de Janeiro, Brasil; RT, 30 segundos [s]), lavadas em água corrente (10 min), coradas com eosina (Dinâmica, Brasil; RT, $15 \mathrm{~s}$ ) e lavadas em água corrente (10 min). Então, as lâminas foram desidratadas em diluições crescentes de etanol (RT, 5 min 70\%, 5 $\min 80 \%, 5 \min 90 \%, 2 \times 5 \min 100 \%$ ), limpas em xilol (Sigma-Aldrich, Wicklow, Ireland; RT, 2 x 10 min) e montadas em Permount® (Fisher-SP15-500). As análises foram feitas em microscópio de luz Olympus®.

\subsection{IMUNOLOCALIZAÇÃO DA ENZIMA CITOCROMO P450 AROMATASE}

A imunohistoquímica foi realizada para localizar os sítios de atuação da enzima citocromo P450 aromatase nos testículos e ovários de preás tratados ou não 
com letrozol. Os cortes em parafina foram desparafinados em xilol (Sigma-Aldrich, Wicklow, Ireland; RT, 2 x $10 \mathrm{~min}$ ) e reidratados em graduação decrescente de etanol (RT, $2 \times 5$ min 100\%; 5 min 90\%, 5 min 80\%, 5 min 70\%). As lâminas foram mantidas em PBS (Thermo Scientific, Dublin, Irlanda; $5 \mathrm{~min}$ ). A recuperação antigênica foi feita usando tampão citrato $(\mathrm{pH} 6,0)$, aquecido em micro-ondas (3 $\mathrm{min})$. Os cortes foram lavados em PBS ( $3 \times 5 \mathrm{~min}$ ). Foi feito o bloqueio da peroxidase endógena (Hydrogen Peroxidase Block, Spring Bioscience, Fremont, USA; RT, $30 \mathrm{~min}$ ). As lâminas foram lavadas em PBS ( $3 \times 5 \mathrm{~min}$ ). Em seguida, foi feito o bloqueio de proteína (Protein Block, Spring Bioscience, Fremont, USA; RT, 1 h). A incubação foi feita com anticorpo primário (anti-aromatase rabbit polyclonal; Abcam ab18995; [1:100 em PBS, $4^{\circ} \mathrm{C}$, overnight]). As lâminas foram lavadas em PBS ( $3 \times 5 \mathrm{~min}$ ) e incubadas com anticorpo secundário (Simple Stain Mouse MAX PO (R), Universal Immuno-peroxidase Polymer for mouse tissues; anti-rabbit; Nichirei Biosciences, Tokyo, Japão). Posteriormente, os cortes foram lavados em PBS ( $3 \times 5 \mathrm{~min}$ ) e incubados em cromógeno DAB (3,3 diaminobenzina; DAB Substrate System, Spring Bioscience, Fremont, USA; RT, 5 min). As lâminas foram lavadas em PBS ( $2 \times 5 \mathrm{~min}$ ) e contra coradas com hematoxilina (Vetec, Rio de Janeiro, Brasil; RT, $30 \mathrm{~s}$ ), passaram por desidratação em diluições crescentes de etanol (RT, $5 \mathrm{~min}$ 70\%, $5 \mathrm{~min}$ 80\%, $5 \mathrm{~min} 90 \%, 2 \times 5 \mathrm{~min}$ 100\%), limpas em xilol (Sigma-Aldrich, Wicklow, Ireland; RT, $2 \times 10 \mathrm{~min}$ ) e montadas em Permount ${ }$ (Fisher-SP15-500). As análises foram feitas em microscópio de luz Olympus ${ }^{\circledR}$.

\subsection{QUANTIFICAÇÃO DA ENZIMA CITOCROMO P450 AROMATASE}

A quantificação da atividade da P450 aromatase foi verificada pelo Western immuno-blotting. Homogeneizamos o tecido ovariano, testicular e a região hipotalâmica, mantidos a $-80^{\circ} \mathrm{C}$, usando um Polytron (PT 3000 KinematicaTM; Brinkman, Westbury, USA) em tampão de lise hipotônico contendo $50 \mathrm{nM}$ de fosfato de potássio ( $\mathrm{pH}$ 7,0); 0,3 $\mathrm{M}$ de sucrose; 0,5 mM dithiothreitol (DTT); $1 \mathrm{mM}$ de ácido etilenodiaminotetraacético (EDTA, pH 8,0); 0,3 mM fluorido fenilmetilsulfonil (PMSF); $10 \mathrm{nM} \mathrm{NaF}$; e coquetel de inibidor fosfatase (1:100; Sigma-Aldrich, Wicklow, Ireland). Determinamos a concentração proteica homogeneizada pelo método Bradford 
(BRADFORD, 1976), seguindo instruções do fabricante (Protein Assay Kit; Biorad, CA, USA) e utilizando a albumina como padrão. Desnaturamos as proteínas (50 $\mu \mathrm{g})$ com tampão Laemmli (15\% glicerina; 0,05 M Tris; 0,055 M bromophenol blue; 9\% SDS) com $6 \%$ de beta-mercaptoetanol (1:1), aquecidos a $95^{\circ} \mathrm{C}$ por 5 minutos.

Determinamos as proteínas em gel unidimensional (SDS-PAGE minigels). As proteínas separadas foram eletro-transferidas para membranas de immunoblot (polivinilideno difluorido; PVDF-BioRad Laboratories) em constantes de $120 \mathrm{~mA}$ por $2 \mathrm{~h}$, a $4^{\circ} \mathrm{C}$, em tampão Tris- $\mathrm{HCl}$ (Tris- $\mathrm{HCl} 12,5 \mathrm{mM}$, glicina, $1 \%$ SDS e metanol $20 \%$ ). Após a transferência, bloqueamos as membranas com $5 \%$ de leite em pó sem gordura em PBS-Tween a 1\% (PBS-T) por 2 h, e incubadas com anticorpo primário anti-aromatase (rabbit polyclonal; Abcam ab18995; [1:100, $4^{\circ} \mathrm{C}$, overnight]). Posteriormente, as membranas foram incubadas com anticorpo secundário (antirabbit IgG peroxidase conjugate [1:2.000; 1h, RT; BioRad, CA, USA). As proteínas foram visualizadas por quimiluminescência (Chemi-Doc®, BioRad, CA, USA) e as imagens foram capturadas pelo software ImageLab® (4.01; BioRad, CA, USA). O tamanho molecular visualizado por bandas foi estimado a partir de um diagrama de tamanho proteico (Kaleidoscope®; BioRad, CA, USA). Utilizamos como padrão de incubação 0 anticorpo primário anti- $\beta$ actina (mouse anti- $\beta$ actina antibody; [1:10.000, 2h, RT] Santa Cruz Biotechnology; Santa Cruz, CA, USA). As membranas foram, então, incubadas com anticorpo secundário (antibody anti-mouse lgG peroxidase conjugate $[1: 2.000,1 \mathrm{~h}, \mathrm{RT}]$; BioRad, CA, USA). As proteínas foram visualizadas por quimiluminescência.

\section{RESULTADOS}

\subsection{EFEITO DO LETROZOL NO GANHO DE PESO CORPORAL}

O ganho de peso corporal foi maior no grupo que ingeriu o letrozol em ambos os sexos e em todas as idades analisadas (Figura 3). 
Figura 3 - Efeito do letrozol no ganho de peso corporal médio de preás fêmeas (A) e machos (B) durante o desenvolvimento sexual, grupos letrozol e controle. ${ }^{*} /{ }^{*} \mathrm{P}<0,05$ : 30 dias vs. 45,90 e 120 dias; ${ }^{\circ} \mathrm{P}<0,05$ : grupo letrozol vs. controle
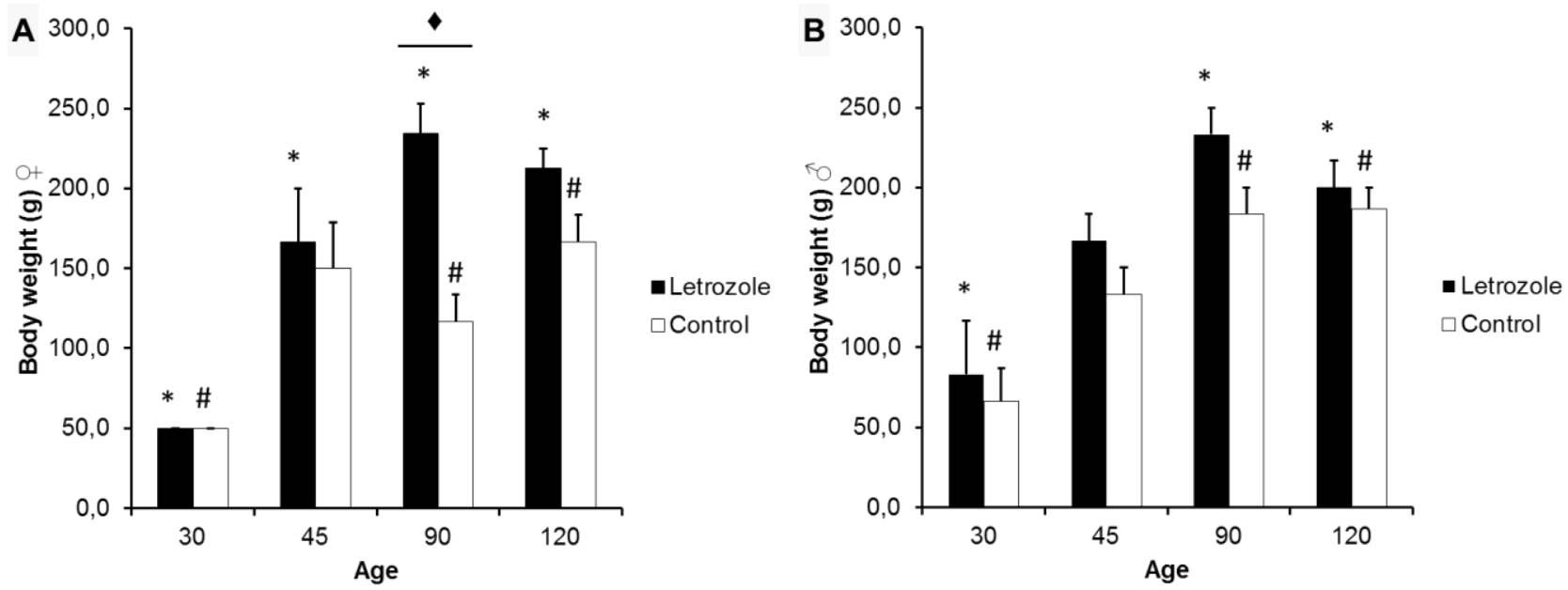

Fonte: (ARROYO, 2017)

\subsection{EFEITO DO LETROZOL NO GANHO DE PESO DO OVÁRIO E DO TESTÍCULO}

O ganho de peso do ovário foi maior no grupo que ingeriu o letrozol em todas as idades analisadas (Figura 4). O ganho de peso do testículo foi maior no grupo que ingeriu o letrozol, exceto aos 45 dias de idade (Figura 4). Não houve significância entre os grupos etários e experimentais.

Figura 4 - Efeito do letrozol no ganho de peso médio do ovário $(A)$ e do testículo $(B)$ de preás durante o desenvolvimento sexual, grupos letrozol e controle. Não houve diferença estatística entre as idades e grupos experimentais
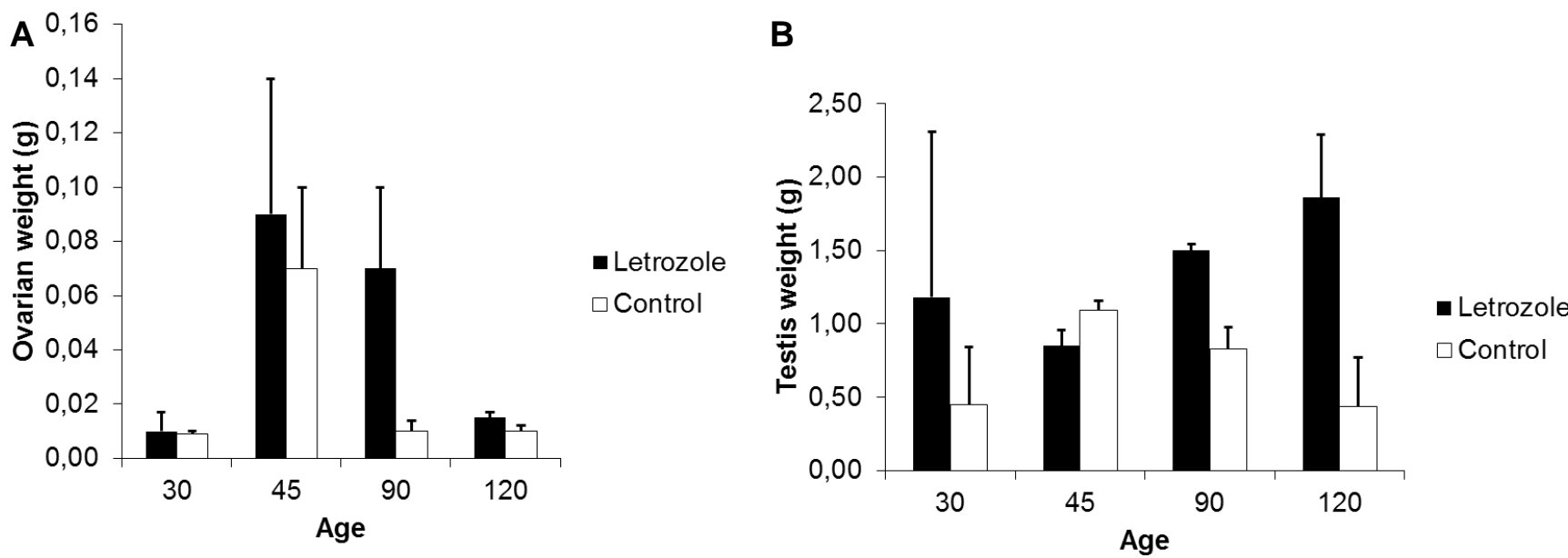

Fonte: (ARROYO, 2017) 


\subsection{EFEITO DO LETROZOL NO GANHO DE PESO DO CÉREBRO}

O ganho de peso cerebral foi maior no grupo que ingeriu o letrozol em ambos os sexos e em todas as idades analisadas (Figura 5).

Figura 5 - Efeito do letrozol no ganho de peso cerebral médio de preás fêmeas (A) e machos (B) durante o desenvolvimento sexual, grupos letrozol e controle. ${ }^{*} / \mathrm{P}<0,0530$ dias vs. $45,90 \mathrm{e}$ 120 dias; não houve significância entre os grupos controle e tratado
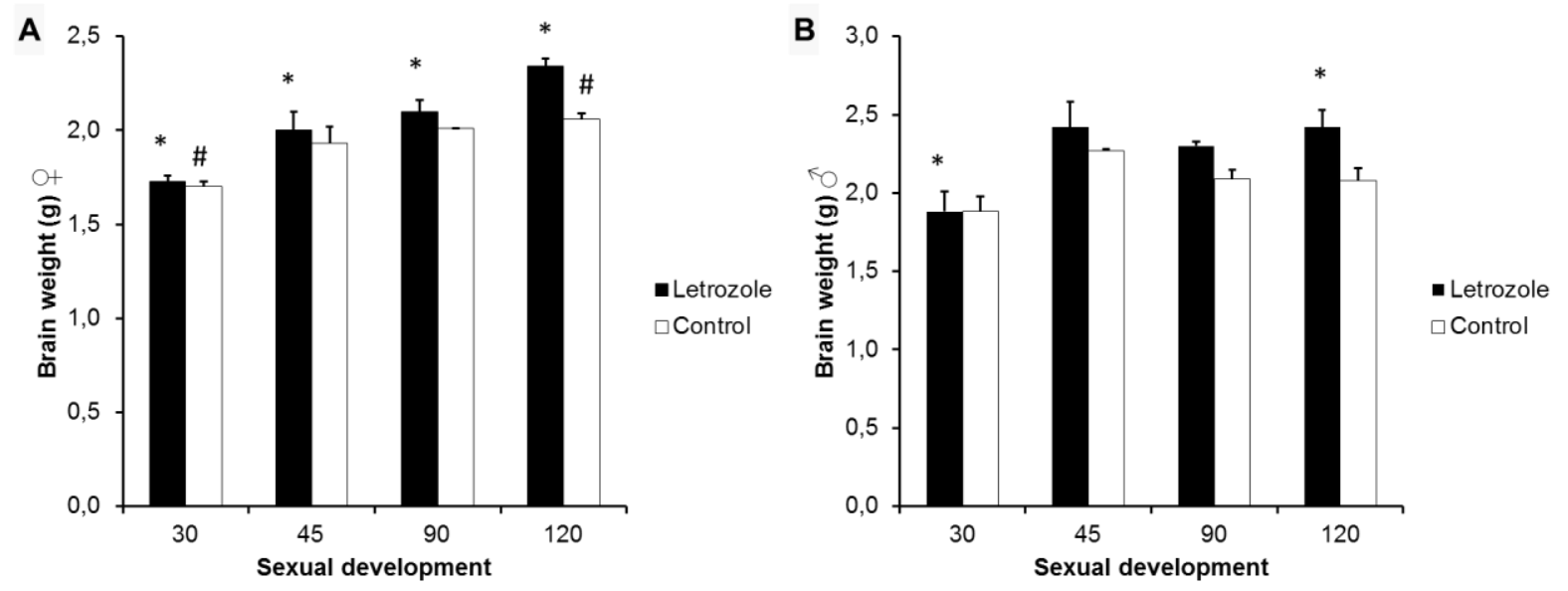

Fonte: (ARROYO, 2017)

\subsection{EFEITO DO LETROZOL NO DESENVOLVIMENTO MORFOLÓGICO DO OVÁRIO}

O letrozol alterou o desenvolvimento morfológico do ovário (Figura 6). A ingestão da droga provocou a estratificação do epitélio de revestimento. Aos 120 dias de idade notamos a formação de micropapilas e uma desordem celular na túnica albugínea. Entretanto, o desenvolvimento folicular não foi prejudicado.

\subsection{EFEITO DO LETROZOL NO DESENVOLVIMENTO MORFOLÓGICO DO TESTÍCULO}


O letrozol regrediu o desenvolvimento morfológico do testículo, afetando a espermatogênese e provocando azoospermia (Figura 7).

Figura 6 - Efeito do letrozol no desenvolvimento do epitélio germinativo do ovário de preás, grupos letrozol (B-E) e controle (A). $(\rightarrow)$ : estratificação do epitélio de revestimento; $\left({ }^{*}\right)$ : desordem celular; (CL): corpo lúteo

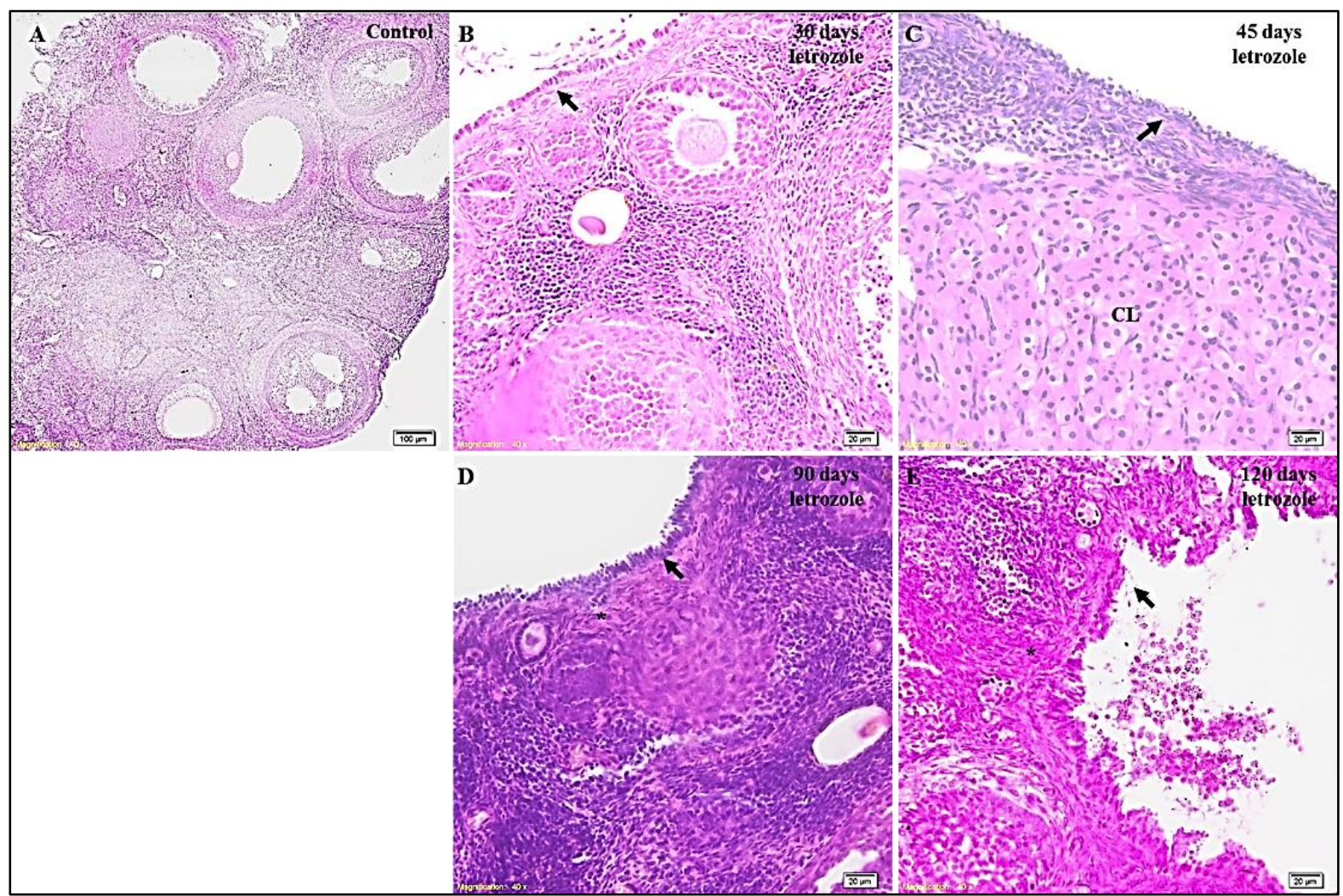

Fonte: (ARROYO, 2017)

Figura 7 - Efeito do letrozol no desenvolvimento do epitélio germinativo do testículo de preás, grupo controle (A-D) e letrozol (E-H), evidenciando a degeneração testicular

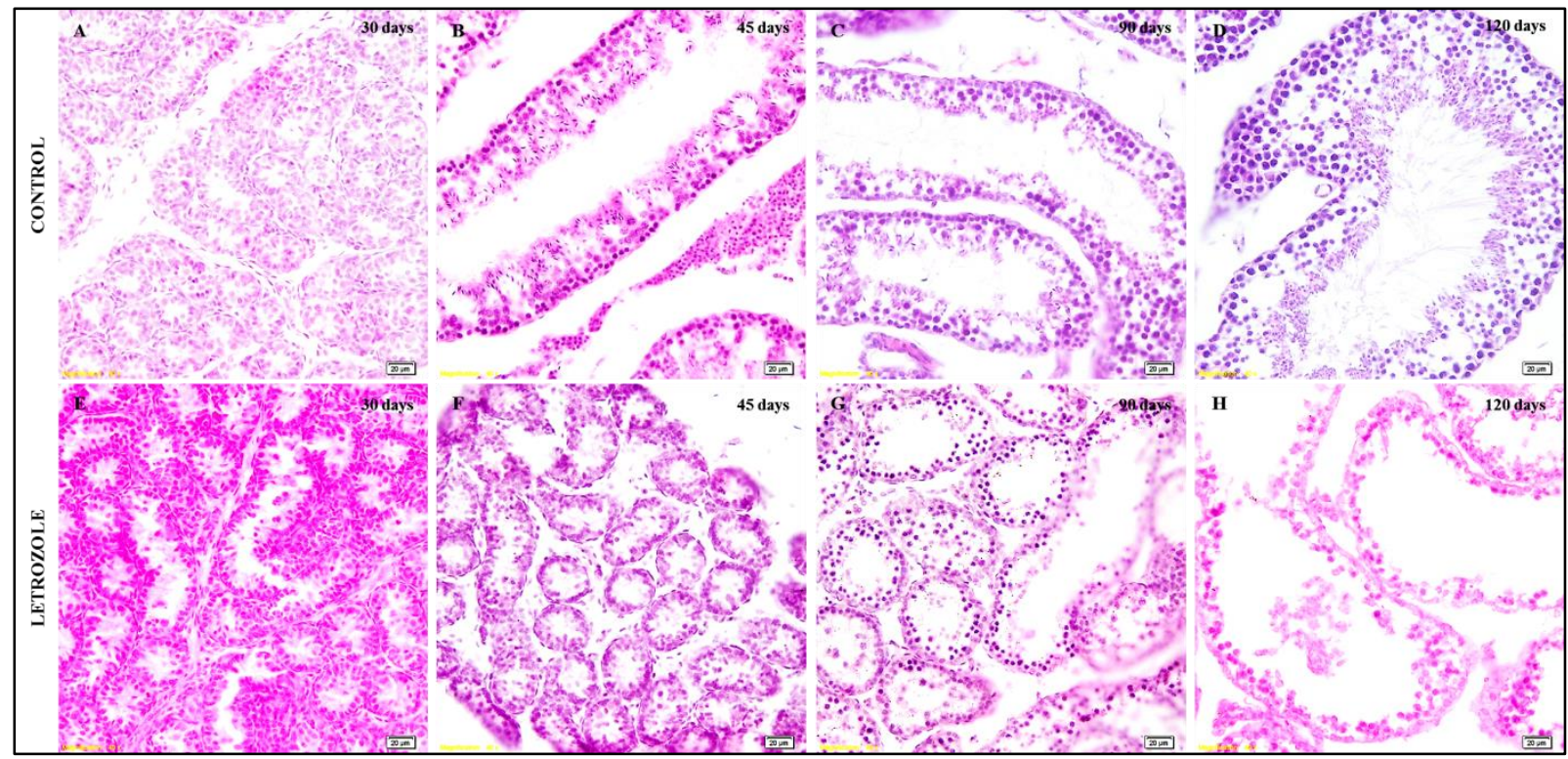

Fonte: (ARROYO, 2017) 


\subsection{EFEITO DO LETROZOL NA MORFOLOGIA CEREBRAL}

Através da análise histológica do corte longitudinal do cérebro, observamos que animais tratados com letrozol possuem a região do hipocampo mais alongada, independente do sexo, aos 30 dias de idade (Figura 8).

Figura 8 - Cérebro de preás machos e fêmeas. Representação esquemática da vista sagital-mediana do cérebro de preá. (I); Hemisfério cerebral direito incluso em parafina (II). (A) Fêmea, grupo controle; (B) Fêmea, grupo letrozol; (C) Macho, grupo controle; (D) Macho, grupo letrozol. (CF): córtex frontal; (Hi): hipocampo; (QO): quiasma óptico

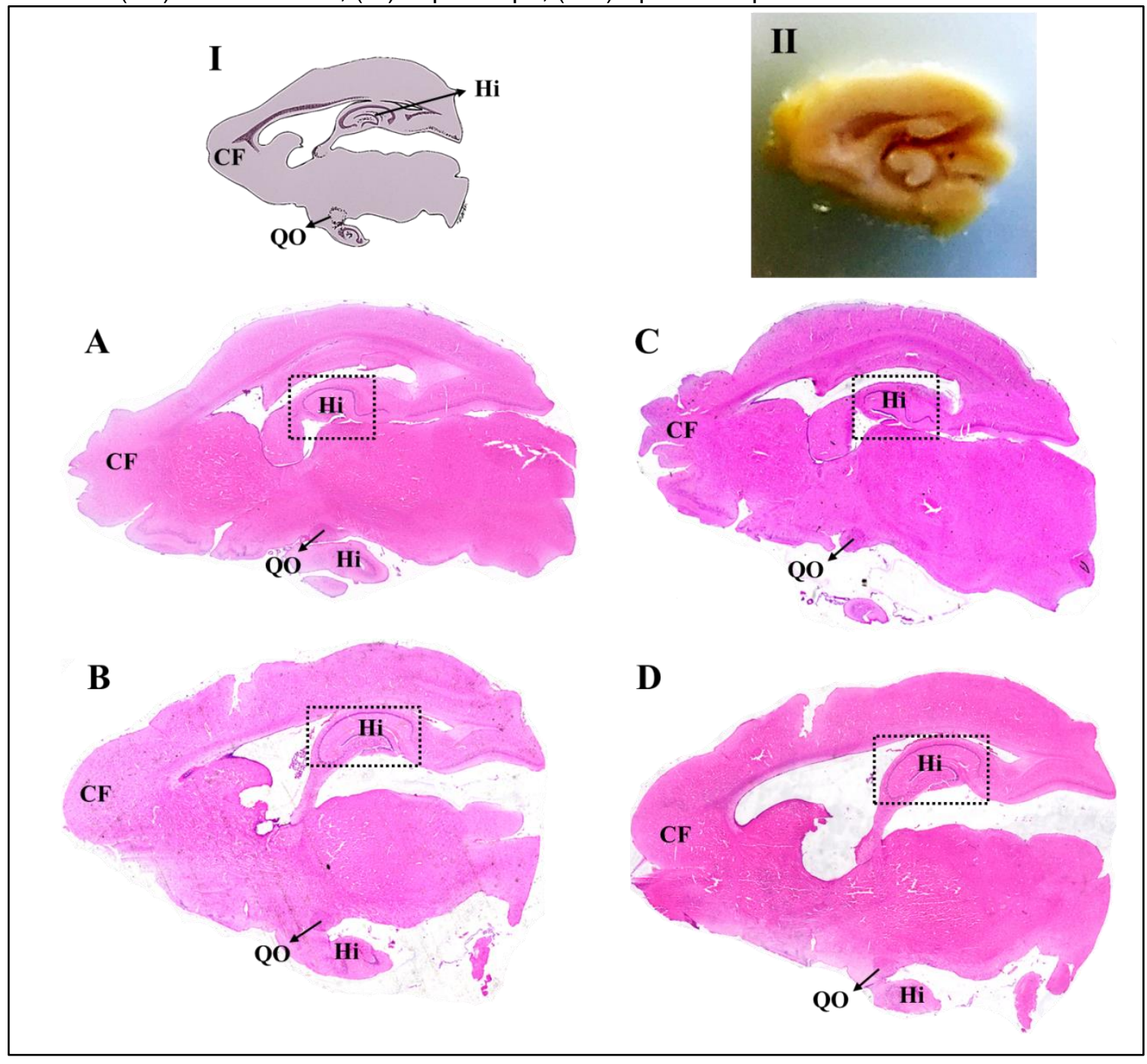

Fonte: (ARROYO, 2017) 


\subsection{EFEITO DO LETROZOL NA IMUNOLOCALIZAÇÃO DA ENZIMA CITOCROMO P450 AROMATASE: OVÁRIO}

O letrozol influenciou a imunolocalização da enzima citocromo P450 aromatase no ovário de preás durante o desenvolvimento sexual (Figura 9; Tabela 2). Aos 90 dias de idade as células da teca interna de animais tratados, bem como os oócitos, eram capazes de aromatizar andrógenos. Por outro lado, nesta mesma idade, fêmeas do grupo controle foram imunonegativas para os mesmos tipos celulares.

Tabela 2 - Imunolocalização da enzima citocromo P450 aromatase no ovário de preás durante o desenvolvimento sexual, grupos controle e letrozol

\begin{tabular}{ccccc|cccc}
\hline Tipo celular & \multicolumn{4}{c|}{ Controle } & \multicolumn{5}{c}{ Letrozol } \\
& 30 & 45 & 90 & 120 & 30 & 45 & 90 & 120 \\
\hline Folículos & + & - & - & - & + & - & - & - \\
Teca interna & - & + & - & - & - & + & + & - \\
Oócito & - & + & - & - & - & + & + & - \\
Estroma & - & + & + & + & - & + & + & + \\
Granulosa & - & + & + & - & - & + & + & - \\
\hline
\end{tabular}

Fonte: (ARROYO, 2017)

Legenda: (+) imunolocalização positiva; (-) imunolocalização negativa.

\subsection{EFEITO DO LETROZOL NA IMUNOLOCALIZAÇÃO DA ENZIMA CITOCROMO P450 AROMATASE: TESTÍCULO}

O letrozol influenciou a imunolocalização da aromatase nos testículos de preás durante o desenvolvimento sexual (Figura 10; Tabela 3). Nos animais sem tratamento, aos 30 dias de idade, as células de Sertoli tinham capacidade de aromatizar andrógenos. A partir dos 45 dias, essa função era exclusiva das células de Leydig, até os 120 dias de idade. Nos preás que ingeriram letrozol, aos 30 e 45 dias de idade, as células de Sertoli e de Leydig foram imunopositivas para a aromatase. Aos 90 dias, as células de Leydig e espermatócitos foram responsivas a presença da enzima. E aos 120 dias de idade apenas as células de Leydig tinham capacidade de aromatizar andrógenos. 
Tabela 3 - Imunolocalização da enzima citocromo P450 aromatase no testículo de preás durante o desenvolvimento sexual, grupos controle e letrozol

\begin{tabular}{ccccc|cccc}
\hline Tipo celular & \multicolumn{4}{c}{ Controle } & \multicolumn{4}{c}{ Letrozol } \\
& 30 & 45 & 90 & 120 & 30 & 45 & 90 & 120 \\
\hline Sertoli & + & - & - & - & + & + & - & - \\
Leydig & - & + & + & + & + & + & + & + \\
Espermatócitos & - & - & - & - & - & - & + & - \\
\hline
\end{tabular}

Fonte: (ARROYO, 2017)

Legenda: (+) imunolocalização positiva; (-) imunolocalização negativa.

Figura 9 - Efeito do letrozol na imunolocalização da enzima citocromo P450 aromatase no ovário de preás, grupos controle (A-D) e letrozol $(E-H)$ durante o desenvolvimento sexual. (s): estroma; (t): teca interna; (a): antro; (o): oócito; (f): folículos primordiais; (cl): corpo lúteo; $(\triangleright)$ : epitélio de revestimento; $(\mathrm{g})$ : células da granulosa. I: controle negativo

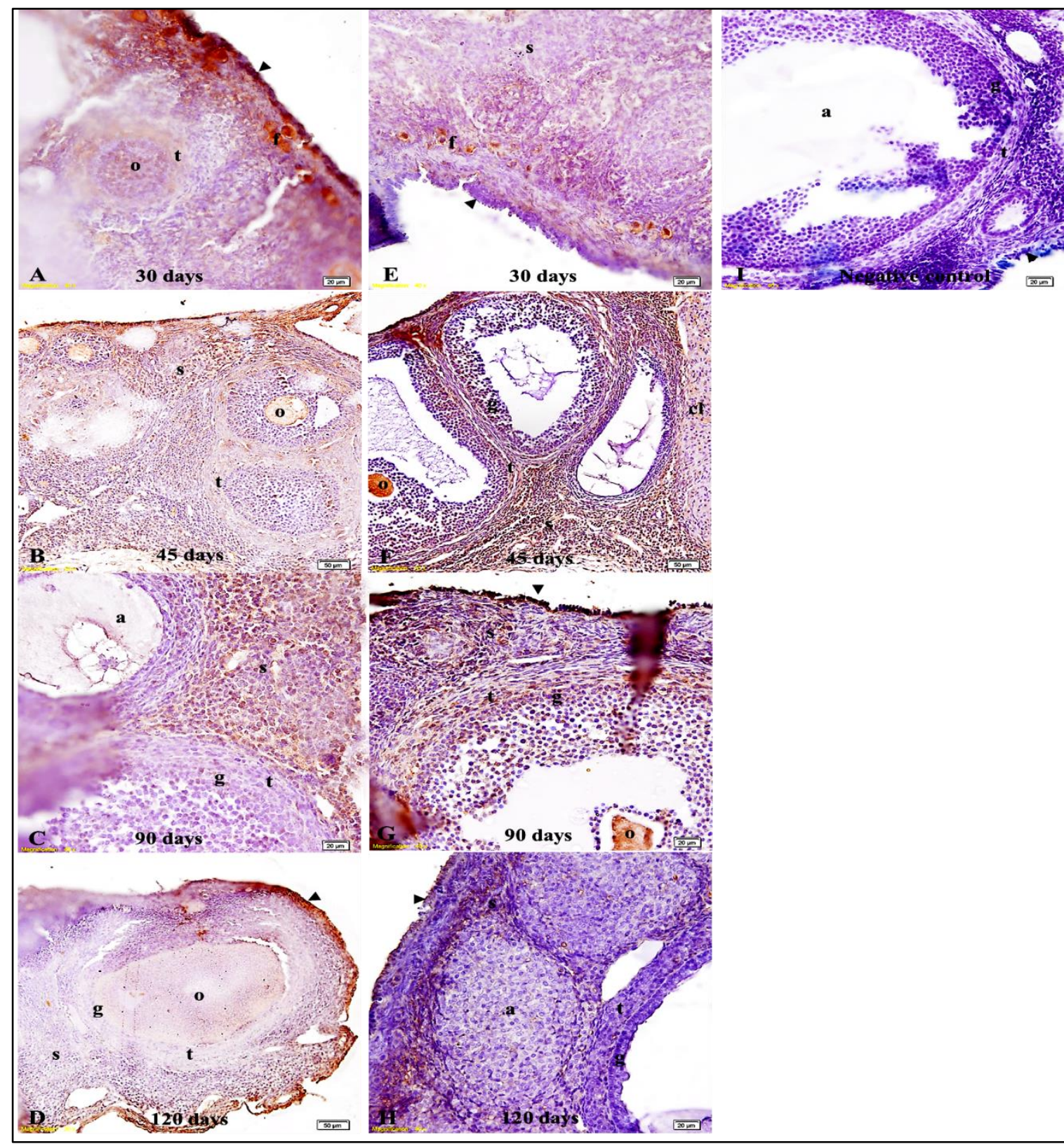

Fonte: (ARROYO, 2017) 
Figura 10 - Efeito do letrozol na imunolocalização da enzima citocromo P450 aromatase no testículo de preás durante o desenvolvimento sexual, grupos controle (A-D) e letrozol (E-H). (S): células de Sertoli; (L): células de Leydig. I: controle negativo

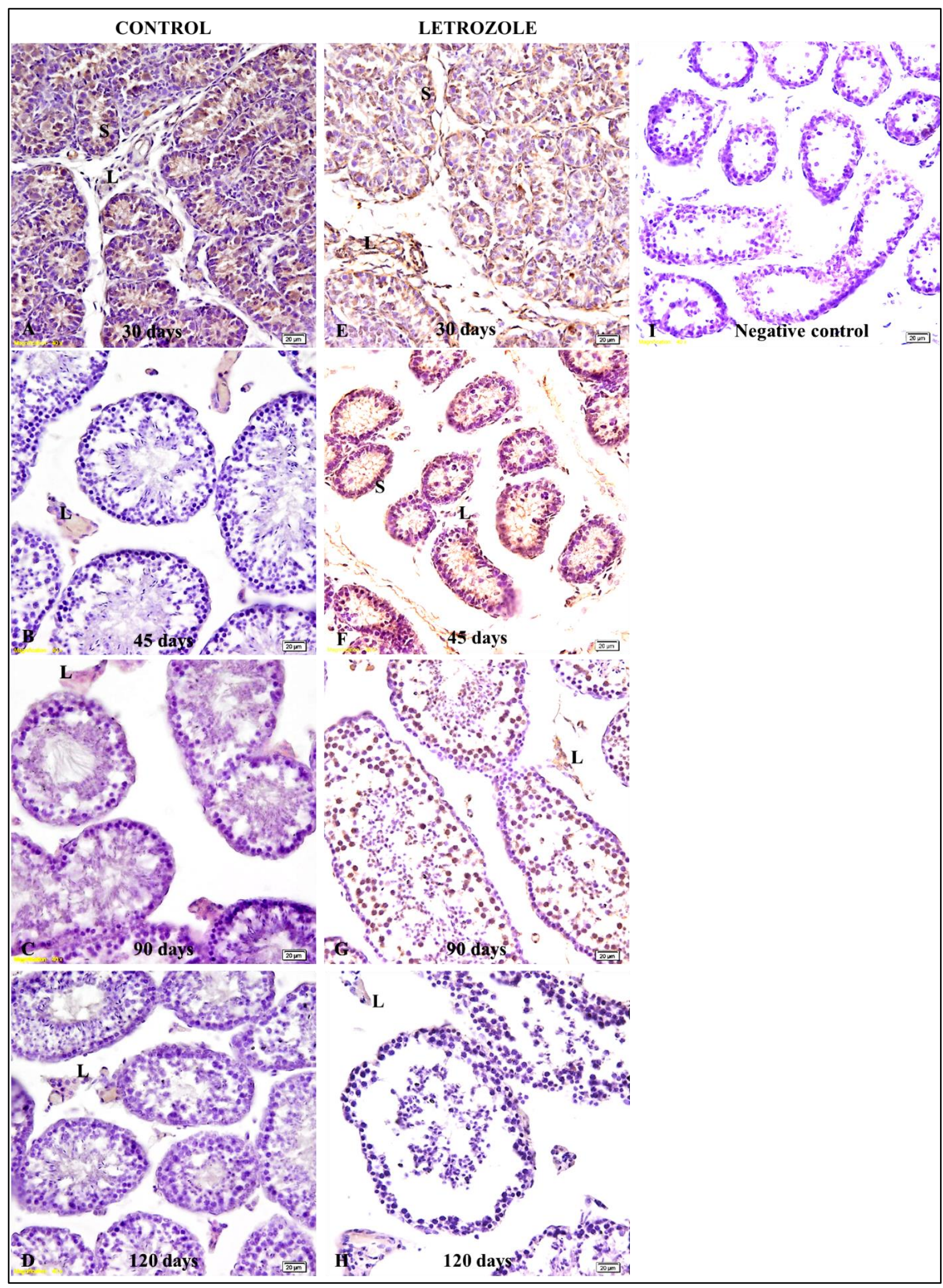

Fonte: (ARROYO, 2017) 


\section{DISCUSSÃO}

Neste estudo nós mostramos, pela primeira vez, os efeitos do letrozol sobre o desenvolvimento morfofisiológico do testículo, do ovário e do cérebro de preás. 0 inibidor aumenta o ganho de peso corporal e das gônadas, bem como induz a infertilidade dos machos e provoca indícios de displasia no ovário. Ainda, altera os sítios de atuação da aromatase nas gônadas. Também revelamos os efeitos do letrozol sobre características neuroreprodutivas de preás machos e fêmeas. inibidor aumenta o ganho de peso do cérebro durante o desenvolvimento sexual e altera a morfologia da região do hipocampo em ambos os sexos aos 30 dias de idade.

O letrozol acarreta um desequilíbrio na razão de hormônios esteroides sexuais, uma vez que induz a redução dos níveis de estrógenos pelo bloqueio da ação da enzima citocromo P450 aromatase (BHATNAGAR, 2007). Assim sendo, a diminuição contínua dos níveis estrogênicos pelo uso prolongado do inibidor como terapêutico para tratamento de enfermidades reprodutivas (RAMBHATLA; MILLS; RAJFER, 2016) provoca alterações no ganho de peso e no desenvolvimento reprodutivo em ambos os sexos.

O aumento no ganho de peso corporal, das gônadas e do cérebro dos animais tratados pode ser explicado pelo provável aumento dos níveis de andrógenos, tanto a nível tecidual quanto periférico (MARECK et al., 2005; ORTEGA et al., 2013). O nosso resultado é suportado por outros semelhantes, nos quais também observaram um aumento no ganho de peso de ratos machos tratados com letrozol (ESHET et al., 2004), bem como nas fêmeas (POULIOT et al., 2013) e no ovário (ORTEGA et al., 2013). Da mesma forma, o uso do antiestrogênico fulvestrant acarretou em ratos machos mais pesados, assim como os testículos (OLIVEIRA et al., 2001). Em contrapartida, o letrozol causou a redução do ganho de peso de ratos machos em doses abaixo de $0,003 \mathrm{mg} / \mathrm{kg}$ (POULIOT et al., 2013). Sugerimos estudos comparativos entre os níveis de testosterona e estradiol, bem como do FSH (hormônio folículo-estimulante) e LH (hormônio luteinizante) sob o efeito do letrozol para melhor compreender os mecanismos de retroalimentação voltados à reprodução de preás. A avaliação destes hormônios melhor elucidaria os nossos achados. 
Ainda, nós demonstramos que o uso prolongado do letrozol em preás modificou o desenvolvimento da espermatogênese, ocasionando degeneração testicular. Em ratos, o efeito da redução dos níveis estrogênicos na espermatogênese resultou em enforcamento das células germinativas, formação de células gigantes e de vacúolos no epitélio seminífero, além de conglomerados de células em degeneração, invaginação de membrana e acúmulo de lipofuscina nas células de Leydig (KONDAREWICZ et al., 2011; PILUTIN et al., 2014).

Não obstante, nas fêmeas de preás nós observamos que o letrozol estratificou o epitélio de revestimento do ovário, mas sem alterar a foliculogênese. Consideramos que períodos longos de ingestão do letrozol causa displasia em fêmeas. Este achado é sustentado por outros autores, os quais evidenciaram os efeitos do letrozol (ORTEGA et al., 2013) e do antiestrogênico tamoxifen (LIMA et al., 2014) no ovário, incluindo a proliferação e formação de multicamadas de células epiteliais, papilomatoses, contorno irregular e aumento do tamanho do núcleo, e aumento de invaginações epiteliais. Contudo, a ingestão do letrozol por longos períodos pode causar a síndrome do ovário policístico em ratas (MALIQUEO et al., 2013; KAUFFMAN et al., 2015).

Ainda, em ambos os sexos, aos 30 dias de idade, a ingestão do letrozol alterou a morfologia da região do hipocampo. O equilíbrio dos níveis de aromatização do sistema límbico tem importante papel na regulação da estrutura do hipocampo, inclusive em roedores. Os altos níveis de andrógenos são capazes de modular a função desta região, podendo afetar, inclusive, a memória (QIU et al., 2016). Além disso, o hipocampo é capaz de sintetizar estrógenos (FESTER et al., 2012). Portanto, o uso do letrozol pode alterar o campo neural exposto às zonas de aromatização, afetando, assim, os fatores relacionados ao comportamento sexual.

O letrozol modificou os sítios de atuação da aromatase nas gônadas de preás. Isto provoca questionarmos se poderia haver uma compensação fisiológica devido às alterações morfológicas ocasionadas pelo consumo do inibidor por longos períodos. Em machos sem tratamento a atividade da aromatase corrobora com outros estudos em roedores (CONLEY; HINSHELWOOD, 2001). Já em fêmeas nas mesmas condições, além das células da granulosa e dos folículos primordiais (SANTOS et al., 2017), as células da teca interna, do estroma e oócito demonstraram serem capazes de aromatizar hormônios androgênicos. Estudos 
complementares, visando quantificar a atividade da aromatase nas gônadas em igual circunstância do atual estudo, poderiam esclarecer os nossos achados.

O presente estudo é clinicamente importante, uma vez que o letrozol é amplamente difundido como terapêutico alternativo para descompensações hormonais em ambos os sexos (ORTEGA et al., 2013; VERMA; KRISHNA, 2016), e vem sendo testado para indução da ovulação e sincronização de cio em ratas (ÇELIK et al., 2004) e bezerras (YAPURA et al., 2014). Ainda, mostramos que o letrozol, aparentemente, pode ser uma alternativa para contracepção masculina. Estudos mais aprofundados a este respeito são necessários para melhor compreender os efeitos da interrupção do tratamento com letrozol após o seu uso prolongado.

O seu uso até os 120 dias de idade em preás revelou que o inibidor pode inferir no ganho de peso corporal, do testículo, do ovário e do cérebro, e no desenvolvimento reprodutivo, tanto em machos como em fêmeas. Assim, o preá se sobressalta como modelo experimental para estudos de desordens reprodutivas que possam acometer homens e mulheres. Contudo, isso nos permite recomendações para pesquisas aprofundadas acerca dos efeitos esteroidogênicos ocasionados pelo uso prolongado do letrozol.

\section{CONCLUSÕES}

Neste estudo nós mostramos que o letrozol afeta o desenvolvimento sexual de preás, pois promove o aumento de ganho de peso, provoca infertilidade de machos, induz a displasia ovariana em fêmeas, pode alterar os campos neurais relacionados às zonas de aromatização, bem como altera os sítios de atuação da aromatase nas gônadas em longo prazo. 


\section{REFERÊNCIAS}

ADRIAN, O.; SACHSER, N. Diversity of social and mating systems in cavies: a review. Journal of Mammalogy, v. 92, p. 39-53, 2011.

BARRIONUEVO, F. J.; ZURITA, F.; BURGOS, M.; JIMENÉS, R. Developmental Stages and Growth Rate of the Mole Talpa occidentalis (Insectivora, Mammalia). Journal of Mammalogy, v. 85, p. 20-125, 2004.

BHATNAGAR, A. S. The discovery and mechanism of action of letrozole. Breast Cancer Research Treatment, v. 105, p. 7-17, 2007.

BRADFORD, M. M. A rapid and sensitive method for the quantitation of microgram quantities of protein utilizing the principle of protein-dye binding. Anal Biochemistry, v.7, p. 248-54, 1976.

CONLEY, A.; HINSHELWOOD, M. Mammalian aromatases. Reproduction, v. 121, p. 685-695, 2001.

CORBIN, C. G.; BERGER, T.; FORD, J. J.; ROSELLI, C. E.; SIENKIEWICZ, W.; TRAINOR, B. C.; ROSER, J. F.; VIDAL, J. D.; HARADA, N.; CONLEY, A. J. Porcine hypothalamic aromatase cytochrome P450: isoform characterization, sex-dependent activity, regional expression, and regulation by enzyme inhibition in neonatal boars.

Biology of Reproduction, v. 81, p. 388-395, 2009.

ÇELIK, Ç.; GEZGINÇ, K.; AKTAN, M.; ACAR, A.; YAMAN, S. T.; GÜNGÖR, S.; AKYÜREK, C. Effects of ovulation induction on ovarian morphology: an animal study. International Journal of Gynecological Cancer, v. 14, p. 600-606, 2004.

DREA, C. M. Sex and seasonal differences in aggression and steroid secretion in Lemur catta: are socially dominant females hormonally 'masculinized'?. Hormones and Behavior, v. 51, p. 555-567, 2007.

ESHET, R.; MAOR, G.; BEN ARI, T.; BEN ELIEZER, M.; GAT-YABLONSKI, G.; PHILLIP, M. The aromatase inhibitor letrozole increases epiphyseal growth plate height and tibial length in peripubertal male mice. Journal of Endocrinology, v. 182, p. 165-172, 2004.

FESTER, L.; PRANGE-KIEL, J.; ZHOUA, L.; BLITTERSDORF, B. v.; BÖHM, J.; 
JARRY, H.; SCHUMACHER, M.; RUNE, G. M. Estrogen-regulated synaptogenesis in the hippocampus: Sexual dimorphism in vivo but not in vitro. Journal of Steroid Biochemistry and Molecular Biology, v. 131, p. 24-29, 2012.

GARCIA-SEGURA, L. M. Aromatase in the brain: not just for reproduction anymore. Journal of Neuroendocrinology, v. 6, p. 705-712, 2008.

GLICKMAN, S. E.; CUNHA, G. R.; DREA, C. M.; CONLEY, A. J.; PLACE, N. J. Mammalian sexual differentiation: lessons from the spotted hyena. Trends in Endocrinology and Metabolism, v. 17, p. 349-356, 2006.

KAUFFMAN, A. S.; THACKRAY, V. G.; RYAN, G. E.; TOLSON, K. P.; GLIDEWELLKENNEY, C. A.; SEMAAN, S. J.; POLING, M. C.; IWATA, N.; BREEN, K. M.; DULEBA, A. J.; STENER-VICTORIN, E.; SHIMASAKI, S.; WEBSTER, N. J.; MELLON, P. L. A novel letrozole model recapitulates both the reproductive and metabolic phenotypes of polycystic ovary syndrome in female mice. Biology of Reproduction, v. 3, p. 69, 2015.

KONDAREWICZ, A.; KOLASA, A.; ZAWIŚLAK, B.; BARANOWSKA-BOSIACKA, I.; MARCHLEWICZ, M.; WENDA-RÓŻEWICKA, L.; WISZNIEWSKA, B. Testis morphology in rats chronically treated with letrozole, an aromatase inhibitor. Folia Histochemica et Cytobiologica, v. 49, p. 677-689, 2011.

LEPHART, E. D. A review of brain aromatase cytochrome P450. Brain Research Reviews, v. 22, n. 1, p. 1-26, 1996.

LIMA, S.; CLEMENSON, A.; TROMBERT, B.; LECOINTRE, R.; LACOSTE, C. R.; PEOC'H, M.; CHENE, G. Morphological and immunohistochemical analysis in ovaries and fallopian tubes of tamoxifen, letrozole and clomiphene-treated rats. Gynecologic Oncology, v. 290, p. 553-559, 2014.

MALIQUEO, M.; SUN, M.; JOHANSSON, J.; BENRICK, A.; LABRIE, F.; SVENSSON, H.; LONN, M.; DULEBA, A. J.; STENER-VICTORIN, E. Continuous administration of a P450 aromatase inhibitor induces polycystic ovary syndrome with a metabolic and endocrine phenotype in female rats at adult age. Endocrinology, v. 154, p. 434-445, 2013.

MARECK, U.; SIGMUND, G.; OPFERMANN, G.; GEYER, H.; THEVIS, M.; SCHÄNZER, W. Identification of the aromatase inhibitor letrozole in urine by gas chromatography/mass spectrometry. Rapid Community Mass Spectrometry, v. 19, n. 24, p. 3689-3693, 2005. 
OLIVEIRA, C. A.; CARNES, K.; FRANÇA, L. R.; HESS, R. A. Infertility and testicular atrophy in the antiestrogen-treated adult male rat. Biology of Reproduction, v. 65, p. 913-920, 2001.

ORTEGA, I.; SOKALSKA, A.; VILLANUEVA, J. A.; CRESS, A. B.; WONG, D. H.; STENER-VICTORIN, E.; STANLEY, S. D.; DULEBA, A. J. Letrozole increases ovarian growth and Cyp17a1 gene expression in the rat ovary. Fertility and Sterility, v. 99, p. 889-896, 2013.

PILUTIN, A.; MISIAKIEWICZ-HAS, K.; KOLASA, A.; BARANOWSKA-BOSIACKA, I.; MARCHLEWICZ, M.; WISZNIEWSKA, B. The immunoexpression of androgen receptor, estrogen receptors $\alpha$ and $\beta$, vanilloid type 1 receptor and cytochrome P450 aromatase in rats testis chronically treated with letrozole, an aromatase inhibitor. Folia Histochemica et Cytobiologica, v. 52, n. 3, p. 206-217, 2014.

POULIOT, L.; SCHNEIDER, M.; DECRISTOFARO, M.; SAMADFAM, R.; SMITH, S. Y.; BECKMAN, D. A. Assessment of a nonsteroidal aromatase inhibitor, letrozole, in juvenile rats. Developmental and Reproductive Toxicology, v. 98, n. 5, p. 374390, 2013.

PRAXEDES, É. C.; LIMA, G. L.; SILVA, A. M.; APOLINÁRIO, C. A.; BEZERRA, J. A.; SOUZA, A. L.; OLIVEIRA, M. F.; RODRIGUES, A. P.; SILVA, A. R. Characterisation and cryopreservation of the ovarian preantral follicle population from Spix. Reproduction, Fertility and Development, doi: 10.1071/RD15249, 2015.

QIU, L.; ZHAO, Y.; GUO, Q.; ZHANG, Y.; HE, L.; LI, W.; ZHANG, J. Dose-dependent regulation of steroid receptor coactivator-1 and steroid receptors by testosterone propionate in the hippocampus of adult male mice. Journal of Steroid Biochemistry \& Molecular Biology, v. 156, p. 23-31, 2016.

RAMBHATLA, A.; MILLS, J. N.; RAJFER, J. The role of estrogen modulators in male hypogonadism and infertility. Reviews in Urology, v. 18, p. 66-72, 2016.

ROSELLI, C. E.; ABDELGADIR, S. E.; RØNNEKLEIV, O. K.; KLOSTERMAN,S. A. Anatomic distribution and regulation of aromatase gene expression in the rat brain. Biology of Reproduction, v. 1, p. 79-87, 1998.

ROSELLI, C. E.; STORMSHAK, F. Ontogeny of cytochrome P450 aromatase mRNA expression in the developing sheep brain. Journal of Neuroendocrinology, v. 24, p. 443-452, 2011. 
SANTOS, P. R. S.; OLIVEIRA, M. F.; SILVA, A. R.; ASSIS NETO, A. C.

Development of spermatogenesis in captive-bred Spix's yellow-toothed cavy (Galea spixii). Reproduction, Fertility and Development, v. 24, p. 877-885, 2012.

SANTOS, P. R. S.; OLIVEIRA, M. F.; ARROYO, M. A. M.; SILVA, A. R.; RICI, R. E.; MIGLINO, M. A.; ASSIS NETO, A. C. Ultrastructure of spermatogenesis in Spix's yellow-toothed cavy (Galea spixii). Reproduction, v. 147, p. 13-19, 2013.

SANTOS, A. C.; BERTASSOLI, B. M.; VIANA, D. C.; VASCONCELOS, B. G.; OLIVEIRA, M. F.; MIGLINO, M. A.; ASSIS NETO, A. C. The morphology of female genitalia in Galea spixii (Caviidae, Caviinae). Bioscience Journal, v. 30, n. 6, p. 1793-1802, 2014.

SANTOS, A. C.; VIANA, D. C.; BERTASSOLI, B. M.; OLIVEIRA, G. B.; OLIVEIRA, D. M.; BEZERRA, F. V. F.; OLIVEIRA, M. F. Characterization of the estrous cycle in Galea spixii (Wagler, 1831). Pesquisa Veterinária Brasileira, v. 35, p. 89-94, 2015a.

SANTOS, A. C.; VIANA, D. C.; OLIVEIRA, G. B.; LOBO, L. M.; ASSIS NETO, A. C. Intrauterine sexual differentiation: biosynthesis and action of sexual steroids hormones. Brazilian Archives of Biology and Technology, v. 58, n. 3, p. 395-405, 2015b.

SANTOS, A. C.; OLIVEIRA, G. B.; VIANA, D. C.; OLIVEIRA, F. D.; SILVA, R. S.; RICI, R. E. G.; OLIVEIRA, M. F.; ASSIS NETO, A. C.. Development and morphological changes in the vaginal closure membrane throughout gestation in Galea spixii (Rodentia: Caviidae). Microscopy Research and Technique, v. 79, p. 359-364, 2016.

SANTOS, A. C.; CONLEY, A. J.; OLIVEIRA, M. F.; OLIVEIRA, G. B.; VIANA, D. C.; ASSIS NETO, A. C. Immunolocalization of steroidogenic enzymes in the vaginal mucous of Galea spixii during estrous cycle. Reproductive Biology and Endocrinology, v. 15, p. 1-8, 2017.

VERMA, R.; KRISHNA, A. Effect of letrozole, a selective aromatase inhibitor, on testicular activities in adult mice: Both in vivo and in vitro study. General and Comparative Endocrinology, http://dx.doi.org/10.1016/j.ygcen.2016.02.028, 2016.

YAPURA, M. J.; MAPLETOFT, R. J.; PIERSON, R. A.; SINGH, J.; ADAMS, G. P. Effect of vehicle and route of administration of letrozole on ovarian function in a 
bovine model. Reproduction, Fertility and Development, v. 26, p. 1198-1205, 2014. 